\title{
Research on the Innovation of Ideological and Political Education Methods in Colleges and Universities in the Era of Big Data
}

\author{
Alatan, Wang Zhong, Zhang Wenjun, Zhao Limeng, and Lu Jia \\ Baotou Medical College, Inner Mongolia University of Technology, Inner Mongolia, China, 014040
}

Keywords: big data era; colleges and universities; ideological and political education; method innovation

\begin{abstract}
The ideological and political education is an important part of the education system in colleges and universities, which has an extremely important educational significance for the improvement of college students' ideological and moral cultivation and scientific culture and the formation of the concept of life values. Under the background of big data era, ideological and political education in colleges and universities should continue to cater to the current development trend of the times and innovate and improve their own educational methods in order to better improve the level of ideological education and the quality of education. This paper expounds the value of innovative ideological and political education methods in colleges and universities in the era of big data, analyzes the impact of the era of big data on the innovation of ideological and political education methods in colleges and universities.
\end{abstract}

\section{Introduction}

Big data is based on information network technology and modern science technology. It efficiently integrates and optimizes data in a certain area, so as to optimize the adjustment of data structure and improve the application value and information value of data. It can be said to be the front-line performance of data analysis technology, and it can lay a good data foundation for the development of various industries, and further guide its development in the direction of standardization and precision [1]. Big data can achieve scientific integration of information through diversified data collection methods, and most of the information comes from a huge data organization system, which can accurately record the development status of an industry in the field and develop the industry. Big data collection methods are innovative and breakthrough in terms of form, content, and technology. Especially in the processing speed of information, big data and traditional data processing methods are essentially different. The characteristics of big data mainly include the following three aspects, as showed in Fig1. Under the background of the current information age, big data as a new data processing technology will lead to new changes in the field of technology and in-depth development.

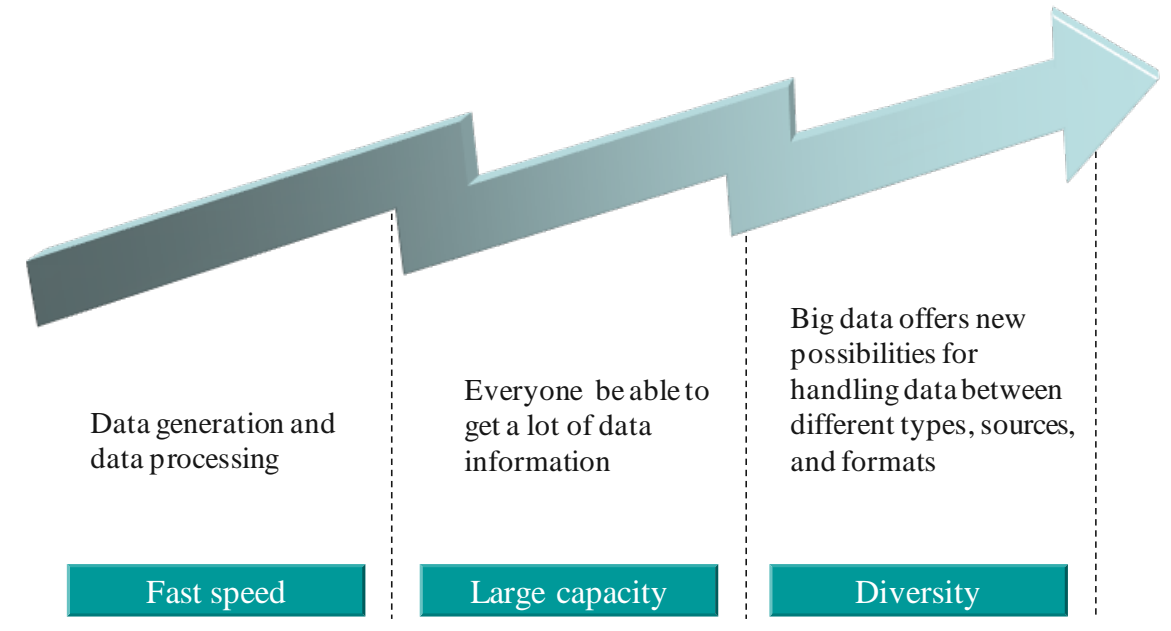

Fig. 1 Features of big data 


\section{The Value of Innovation of Ideological and Political Education in Colleges and Universities in the Era of Big Data}

\subsection{Providing new opportunities for the innovation}

From the microscopic perspective, in the age of big data, ideological and political educators in universities can conduct data analysis on students' ideological conditions, behaviors, values, and other content, and explore the influencing factors in order to formulate effective ideological education. From the macro perspective, big data further urges the ideological and political education system in universities to develop in the direction of information, so as to provide timely data acquisition, follow-up analysis, and forecast of college students' thinking and behavior, and to promote the healthy development of college students. Lay the foundation. It can be seen that using big data as an information acquisition channel can further ensure the authenticity and accuracy of ideological education content in universities, and more accurately grasp the causes of recent student ideological fluctuations, making the formulation of solutions more scientific and concrete [2].

\subsection{Laying a solid foundation for the innovation}

At present, college students are more inclined to engage in emotional communication through the Internet, social media, etc. The information generated by them is an objective manifestation of the college students' thoughts, feelings, values, and behaviors. In this regard, college ideological educators must pay close attention to big data and explore the emotions of students in the Internet platform and mobile terminal based on this, and formulate effective ideological and political education programs to make ideological education programs and educational methods more relevant to students real life, to communicate with students in thoughts and emotions in a highly humane way to ensure that the ideological education in universities is well-targeted. At the same time, when integrating, screening, and processing all the contents of a university student's growth process, students can explore the inner world of the students more precisely and scientifically assess and accurately predict the development of students' thoughts in a certain period of time [3]. Based on the principle of adhering to the principle of advancing in a step-by-step manner and teaching students in accordance with their aptitude, students are given ideological and political education based on their own interests, and they are encouraged to improve their ideological and moral cultivation in the influence of subtle influence, and guide students to continuously improve their own ideological personality. In addition, Big Data ideological education can expand the traditional education approach, and has a good role in promoting the innovation and development of ideological and political education in colleges and universities.

\section{The Influence of Big Data Era on the Innovation of Ideological and Political Education in Colleges and Universities}

\subsection{From directional research to quantitative research}

The era of big data has greatly changed the way of Ideological and political education in Colleges and universities, and promoted the transformation of ideological and political education from orientation research to quantitative research. As far as the current situation of ideological education in colleges and universities is concerned, the traditional way of ideological and political education still occupies a dominant position. Although it has achieved more significant educational results in the application process, it has mostly used questionnaire surveys, theoretical discussions, and observation records. It is difficult to fundamentally discover the practical problems existing in the ideological consciousness of college students, especially for some of the potential hidden problems. The scientific application of big data can effectively solve the practical problems existed, and provide a solution to the limitations of traditional ideological and political education methods, and use computation and data processing methods to obtain the dynamics of college students' thoughts and behaviors. Analyze the value concept of a group of students and improve the scientific nature of ideological education on the basis of quantitative analysis. 


\subsection{From linear relations to nonlinear relations}

The era of big data is prompting the transformation of ideological education from a linear to a non-linear relationship. The traditional ideological and political education is based on the characteristics of linear relationships. Through the analysis of the main line of causality, the correctness of students' ideological behaviors is determined, and the Why problem in ideological and political education is emphasized. This leads to the problem of insufficient in ideological and political education methods in universities. Only in the era of big data can the ideological and political education of universities be able to scientifically record and meaningfully analyze the contents of the educated, and explore the essential content of the data in a non-linear manner in front of massive amounts of data. From this perspective, the ideological and political education methods based on big data are more inclined to analyze the factors related to the educators.

\subsection{From the local scope to the overall field}

The era of big data has prompted the ideological and political education methods in universities to expand from the local scope to the overall field. Affected by the traditional education concept, most ideological and political educators in colleges and universities are still deconstructing the students' mind and behavior with a partial vision. The proportion of local sampling is higher than the overall analysis, although it has certain scientific basis and theoretical basis, in terms of this kind of local ideological education, it is impossible to fundamentally explore the details of students' physical and mental development, and it is easy to overlook some of the students' key issues [4]. The Big Data ideological education approach can take a holistic view of the students' growth and development in terms of their thoughts, feelings, values, and behaviors, and in a visual way to more intuitively and accurately represent the students' emotional fluctuations at a certain stage. Some of these details are presented to ideological and political educators in universities, which point the way for the comprehensive development of ideological education methods in colleges and universities.

\section{Innovation Strategies of Ideological and Political Education Methods in Colleges and Universities in the Era of Big Data}

\subsection{Optimize the ideological and political education environment.}

Optimize the ideological and political education environment in colleges and universities in the era of big data, and realize the scientific innovation of ideological and political education methods in universities through the influence of the external education environment, so as to strengthen the effectiveness and educational influence of ideological and political education in universities, and to solve the current problems in the ideological education of colleges and universities.

On the one hand, it is necessary to build a ideological and political education platform based on big data to provide a broader space for the development of ideological education in universities. Through the scientific construction of educational environment, it is ensured that the mainstream ideology is better integrated into the students' thoughts, emotions and values concepts, behavioral habits. On the other hand, strengthen the construction of big data ideological and political education environment in universities, create a network culture of ideological education in big data universities, and carry out ideological and political education campaigns in a variety of content and forms on the basis of the education platform to mobilize students' learning initiative and enthusiasm as much as possible. And guide students to consciously accept the content of ideological and political education invisible, which is of vital importance to the improvement of students' ideological and moral cultivation and the construction of a sound personality.

\subsection{Innovate methods of ideological and political education.}

The innovation of ideological and political education methods in colleges and universities in the era of big data will be used as an important way for the stable development of educational systems for ideological and political education in universities and scientific implementation of educational programs. The ideological and political educators in universities should respond to and cater to the 
current trend of the development of big data, and seek innovation and breakthroughs based on the traditional teaching mode [5]. And promote the development of ideological and political education methods in universities in a scientific, three-dimensional, and dynamic manner.

\subsection{Scientifically develop ideological and political education curriculum.}

Scientifically develop colleges and universities in the era of ideological education in the era of big data, using videos, pictures, and music as the main carriers to provide ideological and political education workers in colleges and universities with a good curriculum exchange platform. This is of vital importance to the enrichment and innovation of ideological education in colleges and universities. At the same time, these ideological and political education courses with the characteristics of the times should be presented in a brand-new teaching format to maximize the effectiveness of the ideological education for college students.

\section{Summary}

Big data is not only a technology, but also a way of life, behavior, and thinking. Integrate ideas and methods of big data into practical teaching of ideological and political courses, implement differentiated education, respect students' individual differences, guide students to change their learning methods, stimulate students' interest in learning, develop students' practical abilities and creative abilities, thus to give full play to the main role of ideological and political education in college students' ideological education. In this regard, colleges and universities should continue to innovate ideological and political education methods to improve the level and quality of ideological and political education.

\section{References}

[1] Viktor Mayr-Schönberger, Kenneth Cooke. The Age of Big Data. Zhejiang People's Publishing House, 2013, p.239

[2] Yu Hui, Cong Yanli, Sun Lili. Study on the Innovation of Ideological and Political Education in Colleges and Universities in the New Media Era: Perfecting the "Four Classrooms" of Ideological and Political Education in Colleges and Universities [J]. Theory of Study, 2015(10), p.220

[3] Cui Haiying. Value Dimensions and Realization of Network Ideological and Political Education in Universities in the Era of Big Data[J]. HeiLongjiang Research on Higher Education,2015(3), p.34 